\title{
Sexual Practices, Drug Use Behaviors, and Prevalence of HIV, Syphilis, Hepatitis B and C, and HTLV-1/2 in Immigrant and Non-immigrant Female Sex Workers in Argentina
}

\author{
Christian T. Bautista $\cdot$ Maria A. Pando $\cdot$ Elena Reynaga $\cdot$ Ruben Marone \\ Warren B. Sateren - Silvia M. Montano $\cdot$ Jose L. Sanchez $\cdot$ Maria M. Avila
}

(C) Springer Science+Business Media, LLC 2008

\begin{abstract}
Objective To study socio-demographics, sexual practices, drug use behaviors, and prevalences of HIV, syphilis, hepatitis B and C, HTLV-1 and HTLV-2 in immigrant (foreigner) and non-immigrant (local/native) female sex workers (FSW). Design This was a crosssectional study in immigrant and non-immigrant FSW living in Buenos Aires, Argentina. Participants were interviewed using a standardized questionnaire. Results A total of 625 FSW were enrolled, of whom 169 (27\%) were immigrant FSW from Paraguay, the Dominican Republic, Brazil, Peru, and Uruguay. The prevalence of syphilis and hepatitis C was significantly higher among Argentinean FSW than among immigrant FSW. However, hepatitis B prevalence was higher among immigrant FSW. Adjusted risk factor analysis comparing immigrant FSW with Argentinean FSW indicated that marital status (single), occupation (none), fee per sex act ( $\leq$ US\$7), workplace (bar and cabaret), and anal sex with clients were significantly associated with immigrant FSW status. Conclusions Effective HIV/STI
\end{abstract}

C. T. Bautista $(\square) \cdot$ W. B. Sateren

US Military HIV Research Program at the Walter Reed Army Institute of Research, 1 Taft Court, Suite 250, Rockville, MD 20850, USA

e-mail: cbautista@hivresearch.org

C. T. Bautista $\cdot$ S. M. Montano - J. L. Sanchez

US Naval Medical Research Center Detachment, Lima, Peru

M. A. Pando - M. M. Avila

Centro Nacional de Referencia para el SIDA, Departamento de Microbiología, Facultad de Medicina, Universidad de Buenos Aires, Buenos Aires, Argentina

M. A. Pando

Institute of Human Virology, University of Maryland

Biotechnology Institute, Baltimore, MD, USA prevention and medical care programs need to be tailored to the specific needs of both FSW groups in Argentina.

Keywords Immigrant · Migration · Risk - Behavior . Sex worker $\cdot$ HIV $\cdot$ STI $\cdot$ Argentina

\section{Introduction}

In Southeast Asia and sub-Saharan Africa, human mobility has facilitated the spread of HIV infection [1]. Poverty, anonymity, unemployment, social stigma, lack of resources, and economic instability are contributing factors leading women to commercial sex work/prostitution. These same factors may lead to migration to other countries $[2,3]$. Immigrant female sex workers (FSW) constitute a vulnerable group in new environments for many reasons, including lack of familiarity/contact with legal systems, health regulations and immigration laws [4]. Because immigrant FSW are commonly excluded from local

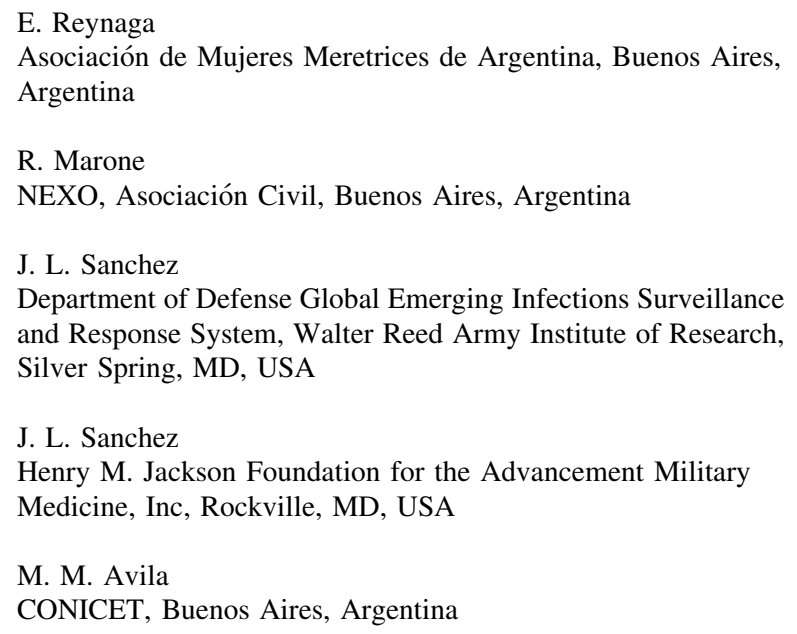


prevention and medical care programs, they may be at higher risk for HIV and other sexually transmitted infections (STI) in comparison with non-immigrant (local/ native) FSW [5, 6].

In South America, recent studies have reported that the HIV prevalence among FSW is highest in Brazil, followed by Argentina, Paraguay, and Ecuador [7, 8]. However, the study of HIV and STI-risk related factors has not been undertaken in immigrant FSW to any great extent. Limited epidemiological studies among immigrant FSW groups have noted positive behavioral changes, especially in condom use for vaginal and anal sex among Asian FSW in Sydney [9], and consistent condom use among Latin American FSW in Madrid [10].

Approximately 130,000 people are living with HIV in Argentina, where injecting drug users (IDU), men who have sex with men (MSM), and FSW are the risk groups most affected by the epidemic [7]. In a previous study among FSW in Argentina, the prevalences of HIV, hepatitis B (HBV), hepatitis C (HCV), human T-cell lymphotropic virus type 1/2 (HTLV-1/2), and syphilis were reported [11], however, the HIV/STI-related risk behaviors among immigrant FSW have not been described in detail. Therefore, this report studies the socio-demographic characteristics, sexual practices, drug use behaviors, and the prevalences of HIV and other STIs between immigrant and non-immigrant (local/native Argentinean) FSW in Argentina.

\section{Methods}

Setting and Study Population

HIV prevalence studies were conducted among FSW in six cities of Argentina (Buenos Aires, Salta, Rosario, Córdoba, Mendoza, and La Plata) during the years 2000-2002. Study methods and HIV/STI prevalences of these studies have been described elsewhere [11]. Briefly, FSW (defined by UNAIDS [12] as: women who receive money or goods in exchange for sexual services, either regularly or occasionally, and who may or may not consciously define those activities as income generating) $\geq 18$ years of age were eligible for this study. FSW were contacted by trained social health workers, peer risk group counselors, and by other FSW at their working locations (brothels, saunas, massage houses, parks, discos/bars, and streets) in each city. Following documentation of written informed consent, FSW participated in a confidential interview on-site by either a psychologist or health care worker with experience in HIV/STI prevention. Information on sociodemographic characteristics, sexual practices, previous STI, and drug-related risk behaviors were collected using a standardized questionnaire. Participants then provided a venous blood sample for HIV/STI screening, and received HIV/STI counseling.

All HIV-positive participants were referred to an infectious disease clinic for further clinical assessment and provision of anti-retroviral treatment. No information on potential (i.e., subjects approached) versus actual participants was collected.

For the purposes of this study, immigrant status was based on self-report of the country of origin. Non-immigrant FSW were defined as local/native Argentinean FSW, while immigrant FSW were defined as foreign FSW who had moved to Argentina from another country.

\section{Laboratory Testing}

Initial HIV screening was performed by ELISA (GENSCREEN Plus HIV AgAb, BioRad, Marnes la Coquette, France) and by agglutination techniques (Serodia HIV, FUJIREBIO, Tokyo, Japan), followed by the Western blot (WB) assay (Novapath HIV-I, Immunoblot, BioRad, CA). Evidence of syphilis infection was determined by a recombinant ELISA (Wiener Laboratories S.A.I.C., Rosario, Argentina). To determine past infection with HCV, anti-HCV testing was performed by ELISA (Wiener Laboratories S.A.I.C., Rosario, Argentina). Exposure to HBV infection was determined by surface antigen and anti-core antibody as determined by ELISA (Wiener Laboratories S.A.I.C., Rosario, Argentina), and an individual was considered positive if at least one of the markers was present. HTLV-1 and 2 antibodies were initially determined by ELISA (BioRad, Marnes la Coquette, France) and by particle agglutination technique (FUJIREBIO, Tokyo, Japan), with confirmation by the WB assay (Genelabs Diagnostics, Science Park, Singapore).

\section{Statistical Analysis}

Chi-square or Fisher's exact test was used to compare categorical variables. Two risk factor analyses comparing immigrant FSW (outcome, code $=1$ ) with non-immigrant (local/native Argentinean, code $=0$ ) FSW were performed. In the first risk factor analysis, odds ratios were adjusted (AOR) for education, time in sex work, number of sexual contacts per week, and condom use with clients using multiple logistic regression. In the second risk factor analysis, a multivariate forward logistic regression with a $P$-value $\leq 0.05$ for entry and $P$-value $\geq 10$ was performed to identify statistically significant independent risk factors associated with immigrant FSW status. For this second analysis, all variables shown in Table 3 were initially 
selected. Statistical analyses were performed using SPSS v.12.0 (SPSS Corporation, IL).

\section{Results}

\section{Study Participants}

A total of $625 \mathrm{FSW}$ were enrolled. Of these, 169 (27\%) were classified as immigrant FSW. Most immigrant FSW were from Paraguay (39\%), the Dominican Republic (32\%), Brazil (10\%), Peru (7\%), and Uruguay (6\%). The highest percentage of immigrant FSW were in the cities of Rosario (80\%, 10/12), La Plata $(62 \%, 62 / 100)$, and Buenos Aires $(32 \%, 94 / 296)$.

Immigrant sex workers had significantly higher proportions of sex acts for lower pay $(<20$ Argentinean pesos,
〜US\$7), bar and cabaret as main work place, vaginal and anal sex with clients, and higher use of alcohol compared with non-immigrant FSW (Table 1). In contrast, significantly higher proportions of non-immigrant FSW (local/ native Argentinean) reported having less education (none or primary only), more sexual contacts per week $(\geq 10)$, street as main work place, inconsistent condom use with clients, previous STI, use of illegal drugs (marijuana and cocaine), inconsistent condom use with partners, and blood transfusion history, compared with immigrant FSW.

HIV and STI Prevalences

Syphilis and HCV prevalence were significantly higher among non-immigrant FSW than immigrant FSW $(51.5 \%$ vs. $30.3 \% ; 5.5 \%$ vs. $1.2 \%$ ). However, HBV prevalence was
Table 1 Socio-demographic characteristics, sexual practices, and drug-related risk behaviors of non-immigrant and immigrant FSW in Argentina
FSW, female sex workers; ARS, Argentinean peso; STI, sexually-transmitted infections; non-immigrant, local/native Argentinean FSW; immigrant, foreigner FSW

* $P$-value by Chi-square or Fisher's exact test

\begin{tabular}{|c|c|c|c|c|c|}
\hline & \multicolumn{2}{|c|}{$\begin{array}{l}\text { Non-immigrant } \\
\text { [local/native }] \\
(N=456)\end{array}$} & \multicolumn{2}{|c|}{$\begin{array}{l}\text { Immigrant } \\
\text { [foreign] } \\
(N=169)\end{array}$} & \multirow[t]{2}{*}{$P$-value* } \\
\hline & No. & $\%$ & No. & $\%$ & \\
\hline \multicolumn{6}{|l|}{ Demographic factors } \\
\hline 18-24 age group (years) & 84 & 18.4 & 41 & 24.3 & 0.131 \\
\hline Single marital status & 230 & 50.4 & 111 & 65.7 & 0.001 \\
\hline Primary education or no education & 303 & 66.4 & 96 & 56.8 & 0.033 \\
\hline Buenos Aires city residence & 202 & 44.3 & 94 & 55.6 & 0.015 \\
\hline No other occupation & 357 & 78.3 & 143 & 84.6 & 0.079 \\
\hline \multicolumn{6}{|l|}{ Sexual factors } \\
\hline$\geq 6$ years in sex work & 288 & 63.2 & 22 & 13.0 & 0.094 \\
\hline$\geq 10$ sexual contacts per week & 275 & 60.4 & 86 & 51.2 & 0.047 \\
\hline$\leq 20$ ARS (US \$7) fee per sex act & 262 & 58.4 & 145 & 87.3 & $<0.001$ \\
\hline Street as primary work place & 320 & 70.3 & 96 & 56.8 & 0.002 \\
\hline Bar as primary work place & 20 & 4.4 & 40 & 23.7 & $<0.001$ \\
\hline Cabaret as primary work place & 13 & 2.9 & 30 & 17.8 & $<0.001$ \\
\hline Oral sex with clients & 291 & 64.0 & 114 & 67.9 & 0.417 \\
\hline Vaginal sex with clients & 365 & 80.2 & 148 & 88.1 & 0.030 \\
\hline Anal sex with clients & 35 & 7.7 & 36 & 21.4 & $<0.001$ \\
\hline Masturbation with clients & 21 & 4.6 & 17 & 10.1 & 0.018 \\
\hline Inconsistent condom use with clients & 94 & 20.7 & 18 & 10.7 & 0.005 \\
\hline Acceptance of extra money for unprotected sex (no) & 37 & 8.7 & 11 & 6.6 & 0.499 \\
\hline \multicolumn{6}{|l|}{$\begin{array}{l}\text { Exposure history (STI, sexual practices, drug use, } \\
\text { blood transfusion) }\end{array}$} \\
\hline Previous STI & 112 & 24.6 & 19 & 11.2 & $<0.001$ \\
\hline Use of illegal drugs & 141 & 30.9 & 16 & 9.5 & $<0.001$ \\
\hline Use of marijuana & 68 & 14.9 & 8 & 4.7 & 0.001 \\
\hline Use of cocaine & 112 & 24.6 & 11 & 6.5 & $<0.001$ \\
\hline Use of alcohol & 192 & 42.1 & 101 & 59.8 & $<0.001$ \\
\hline Inconsistent condom use with steady partners & 213 & 89.5 & 77 & 78.6 & 0.013 \\
\hline Sex with foreigner & 240 & 52.6 & 80 & 47.3 & 0.277 \\
\hline Blood transfusion history & 117 & 25.7 & 22 & 13.0 & 0.001 \\
\hline
\end{tabular}


Table 2 Number of cases and prevalences of syphilis, HCV, HBV, HTLV-1/2, and HIV infection for non-immigrant and immigrant FSW in Argentina

\begin{tabular}{|c|c|c|c|c|c|c|c|}
\hline \multirow[t]{2}{*}{ Infection } & \multicolumn{3}{|c|}{ Non-immigrant [local/native] $(N=456)$} & \multicolumn{3}{|c|}{ Immigrant [foreign] $(N=169)$} & \multirow[t]{2}{*}{$P$-value* } \\
\hline & Number of cases & Prevalence $(\%)$ & $(95 \% \mathrm{CI})$ & Number of cases & Prevalence $(\%)$ & $(95 \% \mathrm{CI})$ & \\
\hline Syphilis & 223 & 51.5 & $(46.7-56.3)$ & 50 & 30.3 & $(23.4-37.9)$ & $<0.001$ \\
\hline Hepatitis C & 24 & 5.5 & $(3.6-8.1)$ & 2 & 1.2 & $(0.2-4.3)$ & 0.038 \\
\hline Hepatitis B & 55 & 12.6 & $(9.6-16.1)$ & 32 & 19.4 & $(13.7-26.3)$ & 0.047 \\
\hline HTLV-1 & 6 & 1.3 & $(0.5-2.9)$ & 3 & 1.8 & $(0.4-5.1)$ & 0.980 \\
\hline HTLV-2 & 1 & 0.2 & $(0.01-1.3)$ & 0 & 0.0 & $(0.0-2.2)$ & 0.999 \\
\hline HIV & 18 & 3.9 & $(2.4-6.2)$ & 2 & 1.2 & $(0.1-4.2)$ & 0.137 \\
\hline
\end{tabular}

HCV, hepatitis C; HBV, hepatitis B; HIV, human immunodeficiency virus; STI, sexually-transmitted infections; HTLV, human T-cell lymphotropic virus; HIV, human immunodeficiency virus; CI, confidence interval; FSW, female sex workers; non-immigrant, local/native Argentinean FSW; immigrant, foreigner FSW

* $P$-value by Chi-square or Fisher's exact test

Table 3 Comparison of characteristics and HIV/STIrelated risk behavior* between immigrant and non-immigrant FSW in Argentina
FSW, female sex workers; STI, sexually-transmitted infections; non-immigrant, local/native Argentinean FSW; AOR, adjusted odds ratio for education, time in sex work, number of sexual contacts per week, and condom use with clients; CI, confidence interval; reference category for odds ratio calculations given in parentheses; significant associations are illustrated in bold face

* Risk factors associated with immigrant status (outcome) versus non-immigrant (local/ native Argentinean) FSW

** $P$-value by multiple logistic regression analysis

\begin{tabular}{|c|c|c|c|}
\hline & AOR & $(95 \% \mathrm{CI})$ & $P$-value $* *$ \\
\hline \multicolumn{4}{|l|}{ Demographic factors } \\
\hline $18-24$, age group ( $\geq 25$ years) & 1.21 & $(0.76-1.92)$ & 0.436 \\
\hline Single, marital status (other) & 1.83 & $(1.23-2.73)$ & 0.003 \\
\hline None or primary education (secondary or higher) & 0.92 & $(0.62-1.36)$ & 0.668 \\
\hline None other occupation & 2.02 & $(1.20-3.40)$ & 0.008 \\
\hline \multicolumn{4}{|l|}{ Sex work } \\
\hline$\geq 6$ years in sex work $(\leq 5)$ & 0.09 & $(0.05-0.14)$ & $<\mathbf{0 . 0 0 1}$ \\
\hline$\geq 10$ sexual contacts per week $(<10)$ & 0.64 & $(0.43-0.95)$ & 0.026 \\
\hline$\leq 20$ ARS (US\$7) fee per sex act $(>20)$ & 4.16 & (2.47-6.99) & $<\mathbf{0 . 0 0 1}$ \\
\hline Street, work place (others) & 0.79 & $(0.53-1.19)$ & 0.258 \\
\hline Bar, work place (others) & 3.68 & $(2.01-6.72)$ & $<\mathbf{0 . 0 0 1}$ \\
\hline Cabaret, work place (others) & 4.73 & (2.29-9.77) & $<\mathbf{0 . 0 0 1}$ \\
\hline Oral sex with clients (no) & 1.46 & $(0.97-2.21)$ & 0.071 \\
\hline Vaginal sex with clients (no) & 1.54 & $(0.87-2.72)$ & 0.136 \\
\hline Anal sex with clients (no) & 2.56 & $(1.37-4.79)$ & 0.003 \\
\hline Masturbation with clients (no) & 2.00 & $(0.96-4.13)$ & 0.063 \\
\hline Inconsistent condom use with clients (always) & 0.49 & $(0.28-0.86)$ & 0.013 \\
\hline Acceptance of extra money for unprotected sex (no) & 0.97 & $(0.41-2.28)$ & 0.941 \\
\hline Sex with foreign clients (no) & 0.67 & $(0.45-0.98)$ & 0.041 \\
\hline \multicolumn{4}{|l|}{$\begin{array}{l}\text { Exposure history (STI, sexual practices, } \\
\text { drug use, blood transfusion) }\end{array}$} \\
\hline Previous STI (no) & 0.58 & $(0.33-1.03)$ & 0.061 \\
\hline Use of illegal drugs (no) & 0.22 & $(0.12-0.38)$ & $<\mathbf{0 . 0 0 1}$ \\
\hline Use of marijuana (no) & 0.21 & $(0.09-0.45)$ & $<\mathbf{0 . 0 0 1}$ \\
\hline Use of cocaine (no) & 0.22 & $(0.11-0.44)$ & $<\mathbf{0 . 0 0 1}$ \\
\hline Use of alcohol (no) & 1.44 & $(0.97-2.14)$ & 0.071 \\
\hline Inconsistent condom use with steady partners (always) & 0.49 & $(0.24-1.04)$ & 0.064 \\
\hline Blood transfusion history (no) & 0.61 & $(0.36-1.04)$ & 0.067 \\
\hline
\end{tabular}

significantly higher among immigrant compared to nonimmigrant FSW (19.4\% vs. 12.6\%). No significant difference in HTLV-1/2 and HIV prevalences were observed in both FSW groups (Table 2).

\section{Risk Factor Analyses}

In the first risk factor analysis (multiple logistic regression), adjusted odds ratios (AOR) significantly associated 
with immigrant FSW when compared with Argentinean FSW were marital status (single, AOR $=1.83$ ), occupation (none, $\mathrm{AOR}=2.02)$, fee per sex act $(\leq 20 \mathrm{ARS}, \leq \mathrm{US} \$ 7, \mathrm{AOR}=$ 4.16), work place (bar, $\mathrm{AOR}=3.68$; cabaret, $\mathrm{AOR}=4.73$ ), and anal sex with clients $($ AOR $=2.56)$ (Table 3$)$. Other adjusted risk factors, such as six or more years in sex work $(\mathrm{AOR}=0.09)$, ten or more sexual contacts per week $(\mathrm{AOR}=0.64)$, inconsistent condom use with clients $(\mathrm{AOR}=0.49)$, use of illegal drugs (any, $\mathrm{AOR}=0.22$; marijuana, $\mathrm{AOR}=0.21$; cocaine, $\mathrm{AOR}=0.22)$, and sexual contacts with foreign clients $(\mathrm{AOR}=0.67)$ were found to be inversely associated with immigrant FSW.

In the second risk factor analysis (multivariate forward logistic regression), independent risk factors found to be significantly associated with immigrant FSW were workplace (bar, OR $=10.62$, 95\% CI = 4.90-23.02; cabaret, $\mathrm{OR}=17.48,95 \% \mathrm{CI}=7.01-43.56)$ and anal sex with clients $(\mathrm{OR}=4.21,95 \% \mathrm{CI}=1.94-9.11)$.

\section{Discussion}

This analysis expands an earlier report on the epidemiology of HIV and other STI among female sex workers in Argentina [11]. Our new findings show that (1) a high proportion of immigrant FSW were from the neighboring countries of Paraguay, Uruguay, and Brazil; the short geographic distances involved and the ease of traveling between these countries and Argentina may explain this high proportion; (2) the prevalence of syphilis and hepatitis $C$ was statistically higher among non-immigrant (local/native Argentinean) FSW than among immigrant FSW, while the prevalence of hepatitis B was higher among immigrant FSW; and (3) single status, no education, anal sex with clients, and bars and cabarets as their main work places were associated with immigrant FSW.

Although prostitution is not technically illegal in Argentina, most cities/provinces have laws allowing the imprisonment of sex workers for "scandalous" behavior in public places; persons found guilty may receive a jail sentence (between 15 and 30 days), a fine, or both (1984 Codigo Penal, Section 32) [13].

In our study, a significant proportion of Argentinean FSW reported use of illegal drugs (any, cocaine, or marijuana). This may suggest that they work in exchange for drugs or they work to get money for drugs. Most Argentinean FSW reported having low educational levels, inconsistent condom use with their clients, a previous STI, and were street workers. Based on these characteristics and sexual behaviors, this group of non-immigrant FSW is at a higher risk of acquiring HIV and other STI.

Recruitment locations for FSW varied by city, although bars and cabarets were reported as the main work places for immigrant FSW, suggesting that this group of FSW prefers an environment with less exposure and more anonymity in order to avoid immigration officers on the streets. Moreover, immigrant FSW from Paraguay and the Dominican Republic are usually less independent than Argentinean FSW, and therefore, are frequently under the control of a "pimp". In addition, FSW who do street work often share drugs with clients and are frequently forced to accept this drug use in order to get work. This occupational hazard may consequently lead to increased exposure to HIV and other STI, and even violence.

Interestingly, most STIs (syphilis, HCV, HTLV-1/2, and HIV), with the exception of hepatitis B were more common among Argentinean FSW compared to immigrant FSW. These differences could therefore reflect different sex and drug behavior patterns between these two groups, such as increased time in sex work, previous STI, inconsistent condom use, or use of illegal drugs. On the other hand, the difference in terms of hepatitis B prevalence among Argentinean and immigrant FSW may be explained in part by the low endemicity of hepatitis B in Argentina compared with the countries of origin of the majority of immigrant FSW [14].

Most immigrant FSW did not have health insurance because of their illegal immigration status, and consequently, did not have access to basic health care services, HIV/STI prevention and treatment $[15,16]$. Effective health care and HIV/STI prevention programs must take into account the different cultural, health, sexual, and ethnic backgrounds of these two FSW risk groups. Recently, a new Primary Health Center catering to FSW was established in La Plata. The development of health care centers like this will provide prevention and health care to FSW without discrimination.

This study has potential limitations. First, it is possible that more established immigrant FSW were underrepresented because of our data collection methods. Second, sensitive sexual and risk behavior information were collected by selfreport, and there may have been underreporting of this data. Third, we were unable to test for curable STIs such as gonorrhea and chlamydia, and for present infection of syphilis and hepatitis B, because of limitations of study funding. Finally, the original study was not designed to study the important dynamics of the commercial sex environment and of qualitative sociological information related to prostitution. Additional data, such as the length of time as an immigrant in Argentina and the frequency of traveling outside the country was not collected, as the primary focus of research was to determine the prevalence of and specific risk factors for various STI. Nonetheless, we believe our study findings have important implications for future research and prevention efforts, as well as suggest additional avenues for public health interventions [17] in Argentinean and immigrant FSW. 
In summary, Argentinean FSW had a higher prevalence of syphilis, hepatitis C, and HIV and more likely to report a longer duration of sex work, more sexual contacts per week, and drug use behavior patterns. While single status, no education, anal sex with clients, and engaging in sex acts for lower pay were more likely to be associated with immigrant FSW, as well as had a higher prevalence of hepatitis B. Our study findings suggest that separate and appropriate HIV/STI prevention programs for immigrant and local/native FSW are required in Argentina.

Acknowledgments Special thanks to all study participants for their collaboration in this study, and to the many staff and scientists at the HIV/AIDS control program and at the "Asociación of Mujeres Meretrices" in Argentina, as well as to Sebastian A. for his technical assitance.

\section{References}

1. Day S, Ward H. Sex workers and the control of sexually transmitted disease. Genitourin Med. 1997;73:161-8.

2. McKeganey NP. Prostitution HIV: what do we know and where might research be targeted in the future? AIDS. 1994;8:1215-26.

3. Ghys P, Jenkins C, Pisani E. HIV surveillance among female sex workers. AIDS. 2001;15 Suppl 3:S33-40.

4. Duckett M. Migrants and HIV/AIDS. Dev Bull. 2000;52:18-20.

5. Foss AM, Watts CH, Vickerman P, Heise L. Condoms and prevention of HIV. BMJ 2004;329:185-6.

6. Harcourt C, Donovan B. The many faces of sex work. Sex Transm Infect 2005;81:201-6.

7. World Health Organization UNAIDS: Report on the global AIDS epidemic, table of country-specific HIV/AIDS estimates and data,
May 2006. Available at: http://www.unaids.org/en/HIV_data/ 2006GlobalReport/default.asp. Accessed 5 Mar 2007.

8. Montano SM, Sanchez JL, Laguna-Torres A, Cuchi P, Avila MM, Weissenbacher M, et al. Prevalences, genotypes, and risk factors for HIV transmission in South America. J Acquir Immune Defic Syndr 2005;40:57-64.

9. Pell C, Dabbhadatta J, Harcourt C, Tribe K, O'Connor C. Demographic, migration status, and work-related changes in Asian female sex workers surveyed in Sydney, 1993 and 2003. Aust N Z J Public Health 2006;30:157-62.

10. Belza MJ, Clavo P, Ballesteros J, Menendez B, Castilla J, Sanz S, et al. Social and work conditions, risk behavior and prevalence of sexually transmitted diseases among female immigrant prostitutes in Madrid (Spain). Gac Sanit 2004;18:177-83.

11. Pando MA, Berini C, Bibini M, Fernandez M, Reinaga E, Maulen $S$, et al. Prevalence of HIV and other sexually transmitted infections among female commercial sex workers in Argentina. Am J Trop Med Hyg 2006;74:233-38.

12. Joint United Nations Programme on HIV/AIDS (UNAIDS): Sex work and HIV/AIDS. Technical update. Geneva: UNAIDS; 2002.

13. 32 Código Penal (1984/1995) Título III Delitos contra la honestidad. Buenos Aires: A-Z Editora; 1984.

14. World Health Organization: Immunization surveillance, assessment and monitoring. Available at http://www.who.int/vaccines/ globalsummary/immunization/countryprofileresult.cfm. Accessed 5 Mar, 2007.

15. Bandyopadhyay M, Thomas J. Women migrant workers' vulnerability to HIV infection in Hong Kong. AIDS Care 2002; 14:509-21.

16. Kerr-Pontes LR, Gonzalez F, Kendall C, Leao EM, Tavora FR, Caminha I, et al. Prevention of HIV infection among migrant population groups in Northeast Brazil. Cad Saude Publica 2004;20:320-28.

17. Bronfman MN, Leyva R, Negroni MJ, Rueda CM. Mobile populations and HIV/AIDS in Central America and Mexico: research for action. AIDS 2002;16 Suppl 3:S42-9. 